[CONTRTBUtion FROM THE Department OF Chemistry, UNiversity OF Wisconsin.]

\title{
THE EFFECT OF DISSOLVED SUBSTANCES ON THE VELOCITY OF CRYSTALLIZATION OF WATER.
}

III. FURTHER EVIDENCE THAT THE EXISTENCE OF HYDRATES IN SOLUTION EXPLAINS THE RETARDING EFFECT OF THE SOLUTE ON THE VELOCITY OF CRYSTALLIZATION OF WATER.

\author{
By ALBERT BRANN.' \\ Received May 7, 1918.
}

In two previous papers ${ }^{2}$ it has been shown that hydration, in all probability, is the biggest factor in the retarding effect of dissolved substances on the V. C. (velocity of crystallization) of water. It was pointed out, however, that some of the data from which conclusions were drawn were obtained in dilute solutions, with the result that the values of the V. C., in many cases, were so close numerically, that the differences might be accounted for by experimental error. Furthermore, the study had been almost entirely limited to the use of inorganic compounds as the retarding agents. Consequently, the present work was undertaken to broaden the scope of the experiments to several distinct and varied classes of compounds, to abolish doubt as to the validity of the results by using more concentrated solutions, and to substantiate the view that hydration in solution is the chief factor in the retardation of the V. C. of water solutions. The problem has been supplemented from a three-fold standpoint: the effects produced by certain classes of (I) inorganic compounds, (2) organic compounds, and (3) colloids.

\section{Experimental.}

Apparatus.-A new apparatus was constructed, differing in several particulars from the old one. ${ }^{3}$ Two of the most important changes are worth mention. The secondary bath was lined inside with sheet tin instead of galvanized iron, because the latter was attacked chemically by the solution in the bath to such an extent that a heavy precipitate formed which interfered with observations in the tube. This bath was also made 3 inches wider so that observation windows could be built into both sides of it. With this arrangement, two tubes can be placed in the bath simultaneously, thus doubling the number of readings in a given time.

Calibration and Choice of Tubes.-Certain difficulties had arisen in connection with the tubes that had been used in the work up to this point. It was therefore decided to make a critical study of different types of tubes in order to determine the best kind of tube for the work. In selecting tubes, 3 important questions arise: (I) What are the effects of

1 Part of a thesis submitted to the graduate school of the University of Wisconsin as partial fulfilment of the requirements for the degree of Doctor of Philosophy

${ }^{2}$ Walton and Brann, THis Journal, 38, 317 (1916); 38, 1161 (1916).

${ }^{3}$ Walton and Judd, J. Phys. Chem., 18, 722 (1914). 
the size of the bore and the thickness of wall on the V.C.? (2) In which type is there the least spontaneous crystallization? (3) Which type will give the most reliable and constant readings?

To determine the effects of these variables, Stone ${ }^{1}$ carried out a series of experiments with a large number of soft glass tubes, selected with particular care as to uniformity of bore and thickness of wall. These were standardized against pure water and $0.5 M$ potassium chloride, but only those which checked closely were used. Table I shows that of the 3 types selected, the tubes of Type $x$ and those of Type 3 had approximately the same thickness of wall, but the diameter of the bore of the former was twice that of the latter. The tubes of Type 2 and those of Type 3 had about the same sized bore, but the walls of the latter were approximately twice as thick as those of the former.

TABLE I.

Showing the Bore and Thickness of Walls of the Three Types of Tubes Used.

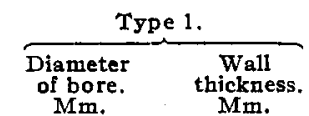

$5 \cdot 6$

5.6

$5 \cdot 5$

$5 \cdot 7$

$5 \cdot 3$

Av., 5.5

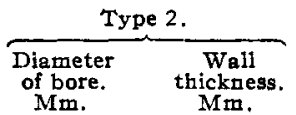

2.8

2.7

2.5

3.0

$\cdots$

2.7
Mm.

I. 2

I. I

I. 3

I. I

$\ldots$

$\mathrm{I}, 2$
Type 3.

$\begin{array}{cc}\begin{array}{c}\text { Diameter } \\ \text { of bore. } \\ \text { Mm. }\end{array} & \begin{array}{c}\text { Wall } \\ \text { thickness. } \\ \text { Mm. }\end{array} \\ 2.5 & 2.2 \\ 2.5 & 2.1 \\ 2.3 & 2.2 \\ 2.3 & 2.2 \\ 2.5 & 2.1 \\ 2.4 & 2.2\end{array}$

Effect of Size of Bore on the V. C.-The results of the standardization are given in Table II. To avoid long tables of data, only the average value of the $V$. C. for a given set of tubes is presented. In every case, the tubes of large bore give the greatest $V$. C. Just what the limits of increase of the V. C. with the size of the bore are, or how it would show itself at temperatures other than those at which these experiments have been made, have not yet been determined.

TABLE II.

The V. C. of Water and of $0.5 \mathrm{M} \mathrm{KCl}$ in the Three Types of Tubes Selected.

\begin{tabular}{|c|c|c|c|}
\hline $\begin{array}{l}\text { Type of } \\
\text { tube. }\end{array}$ & Substance. & $\begin{array}{c}\text { Temperature. } \\
\text { Deg. cent. }\end{array}$ & $\begin{array}{l}\text { Mean V. C.- } \\
\text { cm./min. }\end{array}$ \\
\hline $1 \ldots \ldots \ldots \ldots \ldots \ldots$ & Pure water & -9 & 500 \\
\hline $2 \ldots \ldots \ldots \ldots \ldots \ldots \ldots$ & Pure water & -9 & 256 \\
\hline $3 \ldots \ldots \ldots \ldots \ldots \ldots \ldots$ & Pure water & -9 & 250 \\
\hline I. $\ldots \ldots \ldots \ldots \ldots \ldots$ & $0.5 M \mathrm{KCl}$ & -9 & I 5 \\
\hline $2 \ldots \ldots \ldots \ldots \ldots \ldots$ & $0.5 M \mathrm{KCl}$ & -9 & 93 \\
\hline $3 \ldots \ldots \ldots \ldots \ldots \ldots \ldots$ & $0.5 M \mathrm{KCl}$ & -9 & 104 \\
\hline$r \ldots \ldots \ldots \ldots \ldots \ldots \ldots$ & $0.5 M \mathrm{KCl}$ & -7 & 237 \\
\hline $2 \ldots \ldots \ldots \ldots \ldots \ldots \ldots$ & $0.5 M \mathrm{KCl}$ & -7 & 170 \\
\hline $3 \ldots \ldots \ldots \ldots \ldots \ldots \ldots$ & $0.5 M \mathrm{KCl}$ & -7 & 174 \\
\hline
\end{tabular}


According to Tammann, ${ }^{1}$ it may be stated that the maximum V. C. is attained when the temperature of the bath is such that it will offset the heat evolved during crystallization to such an extent that that portion or layer of liquid in the tube about to crystallize is at its freezing temperature. If the heat evolved during crystallization is, sufficient to raise the temperature of the liquid above its freezing point, the $\mathrm{V}$. C. will be less than the maximum value, and if the heat evolved during crystallization is insufficient to raise the temperature of the liquid up to its freezing point, the V.C. will likewise be less than the maximum value. To sum up the foregoing statements, the $V$. C. attains its maximum value when temperature conditions inside and outside the tube so balance each other as to maintain the crystallizing liquid constantly at the freezing temperature. From this, it must be concluded that, under the temperature conditions of these experiments, the liquid within the larger tubes was nearer the temperature of its freezing point than was that within the smaller tubes, hence a greater value for the $\mathrm{V} . \mathrm{C}$. is obtained in the case of the larger tubes. However, all the factors--such as rate of heat conduction by the liquid and glass, kind of tube material, thickness of wall, etc.that bring about these conditions have not yet been studied. For the present, the facts show that at the temperatures quoted in the table, the $V$. C. is greater the larger the internal diameter.

In conjunction with this, it might be well to point out that the thickness of wall apparently has little effect on the V. C. A study of Table I shows this to be the case. The wall of Type 2 tube is about twice as thick as that of Type 3 , yet the V. C. in both cases is approximately the same.

Effect of Wall Thickness on Spontaneous Crystallization.--The thickness of wall, however, is an appreciable factor from the standpoint of spontaneous crystallization. As has been shown, ${ }^{2}$ the occurrence of spontaneous crystallization seems to depend largely on the nature of the solution. It was observed that this phenomenon occurred very much less frequently with tubes having thick walls than with similar tubes having thin walls. This was probably due to the fact that in the case of the tubes with the thick walls the liquid within cooled at a slower rate. Hence the chance for crystalline nuclei being formed rapidly and the consequent tendency to spontaneous crystallization was lessened.

Effect of Size of Bore on Spontaneous Crystallization.-According to Tammann, ${ }^{3}$ spontaneous crystallization is accompanied by the formation of crystalline nuclei throughout the liquid. It would be expected, then, that the smaller the volume of the liquid, the less would be the chance

\footnotetext{
" "Kristallisieren und Schmelzen," rg07, p. I31.

2 Walton and Brann, This JoUrNal, 38, 317 (1916).

${ }^{3}$ Loc. cit., p. 148 .
} 
for nuclei formation. The present work substantiates this view, for spontaneous crystallization occurred much less often in Types 2 and 3 than in Type $\mathrm{I}$. These findings are also in agreement with the recent work of S. Lawrence Bigelow and Edward A. Rykenboer ${ }^{1}$ on supercooling phenomena.

Partial Prevention of Spontaneous Crystallization.-Frequently spontaneous crystallization took place at points near the open ends of the tube. In the previous work ${ }^{2}$ this was partially offset by placing a layer of paraffin oil on the solution at each end of the tube. It was found that a thick piece of rubber tubing, slipped over each end of the glass tube, was much more effective in stopping spontaneous crystallization than the paraffin oil had been, probably due to the fact that the solution directly enclosed by the tubing was cooled very slowly. The rubber tubing was also much more convenient and saved a great deal of time otherwise spent in cleaning tubes.

Summary of Study with Tubes.-Briefly this study of the tubes may be summarized as follows: Of the 3 types used, the third proved to be the most satisfactory. The tubes of this type slow down the V. C., reduce the tendency to spontaneous crystallization and give the most reliable results. Consequently, selected tubes from a number of Type 3 were used in this investigation.

Temperature at Which Experiments Were Made.-From the above study of the tubes, it was found that $-7^{\circ}$ was the best working temperature. Spontaneous crystallization was less likely to set in at this temperature and this was an important consideration in obtaining reliable readings. All of the later work, therefore, has been conducted at $-7^{\circ}$. Except for this change, the following results were obtained in the same manner as previously described. ${ }^{3}$

Preparation of the Solutions.-The purest chemicals commercially obtainable were employed in making up all the solutions. The description of the preparation of the colloids is deferred till a full discussion of the effect of hydrosols is taken up.

\section{Discussion of Results.}

The Effects Produced on the V. C. by Certain Inorganic Compounds.A great many of the earlier experiments were carried out with dilute solutions only. Although the results obtained were favorable to an explanation based on hydrates in solution, yet some of the data were so close in numerical values that they might not be reliable. A series of experiments was consequently carried out with the more common chlorides

\footnotetext{
1 J. Phys. Chem., 21, 474 (1917).

${ }^{2}$ Walton and Judd, Ibid., 18, 722 1914).

${ }^{3}$ Walton and Brann, Loc. cit.
} 
and sulfates, using solutions of concentrations ranging from $0.5 M$ to the most dilute solution that would give a rational reading.

The results are given in Tables III and IV. Data upon some of the chlorides are graphed in Fig. I. Reproduced, for sake of comparison, is

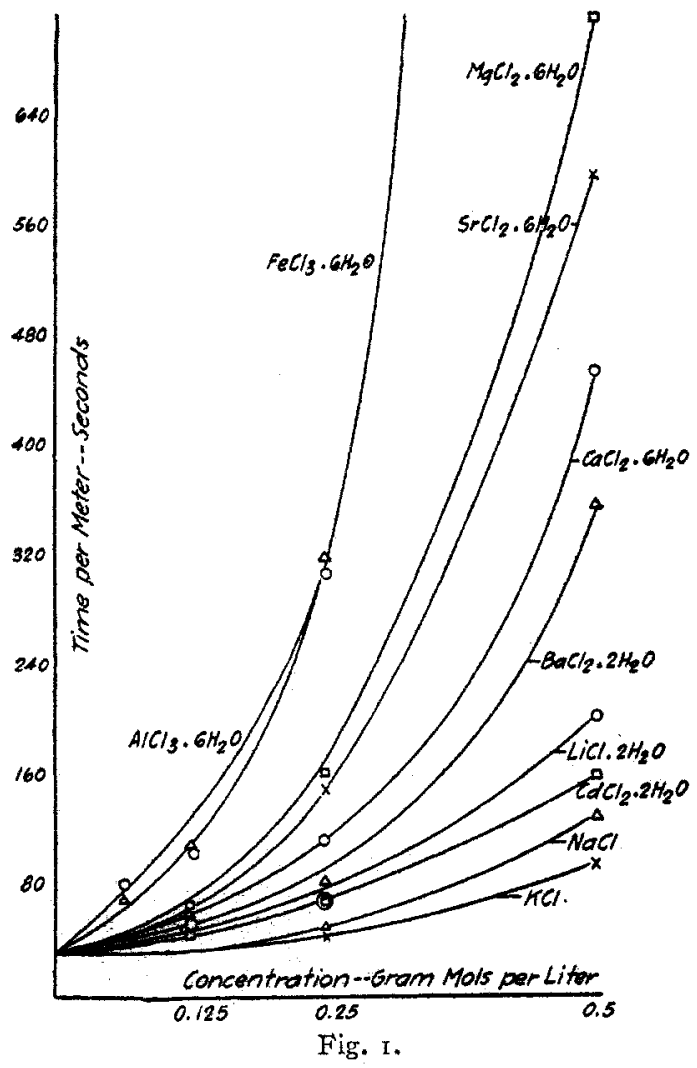

Fig. 2, taken from the work of Jones. ${ }^{1}$ A glance will suffice to notice the close resemblance of this figure and Fig. I. The abnormally large values for the molecular lowering of the freezing point are explained on the basis that hydrates are formed in solution. On the same basis, the results for the V. C. of water can be explained. The chlorides on both figures fall into exactly analogous positions, save that $\mathrm{CaCl}_{2} \cdot 6 \mathrm{H}_{2} \mathrm{O}$ and $\mathrm{SrCl}_{2} .6 \mathrm{H}_{2} \mathrm{O}$ interchange places.

Consider, too, the values obtained for the sulfates listed in Table IV. Here again the results justify explanation on the basis of hydration. $\mathrm{Na}_{2} \mathrm{SO}_{4} \cdot \mathrm{IOH}_{2} \mathrm{O}$ shows greater power for retardation of the V. C. than does $\mathrm{K}_{2} \mathrm{SO}_{4}$. The vitriols used have approximately equivalent retarding effects. However, $\mathrm{CuSO}_{4.5} \mathrm{H}_{2} \mathrm{O}$ and $\mathrm{MnSO}_{4} \cdot 4 \mathrm{H}_{2} \mathrm{O}$ retard the $\mathrm{V}$. C. less than do the sulfates crystallizing with 7 molecules of water.

It is a noticeable fact that analogous phenomena are exhibited with the $\mathrm{V} . \mathrm{C}$. in comparatively dilute solutions as are shown in concentrated solutions by the freezing-point method. This suggests the probability that substances in dilute solutions are hydrated in the same proportional order of magnitude as they are in their more concentrated solutions.

The Relation of the Heat of Solution to the V. C.-A striking parallelism exists between the values of the $\mathrm{V}$. C. and the heats of solution of the different substances used in this investigation, as is readily seen when ${ }^{1}$ Jones, Publ. Carnegie Insi., 60. 
the two sets of values are placed side by side as in Tables III and IV. Analogous parallelisms between heats of solution and relative values of hydration have been pointed out by other investigators. ${ }^{1}$ As Washburn observes, "In cases where the process of solution consists to a large extent of a union between solvent and solute to form one or more hydrates in solution, a parallelism between heat of solution and degree of hydration in certain cases might be expected. The heat of solution of a solid salt is doubtless a composite quantity, including, as it does, the heats of disgregation, of ionization, etc., as well as the heat of hydration, so that a parallelism is the most that could be expected."

The values for the heats of solution listed in Tables III and IV have been taken from Landolt and Bömstein's "Tabellen," edition of I9I2. Although these values were not obtained ex-

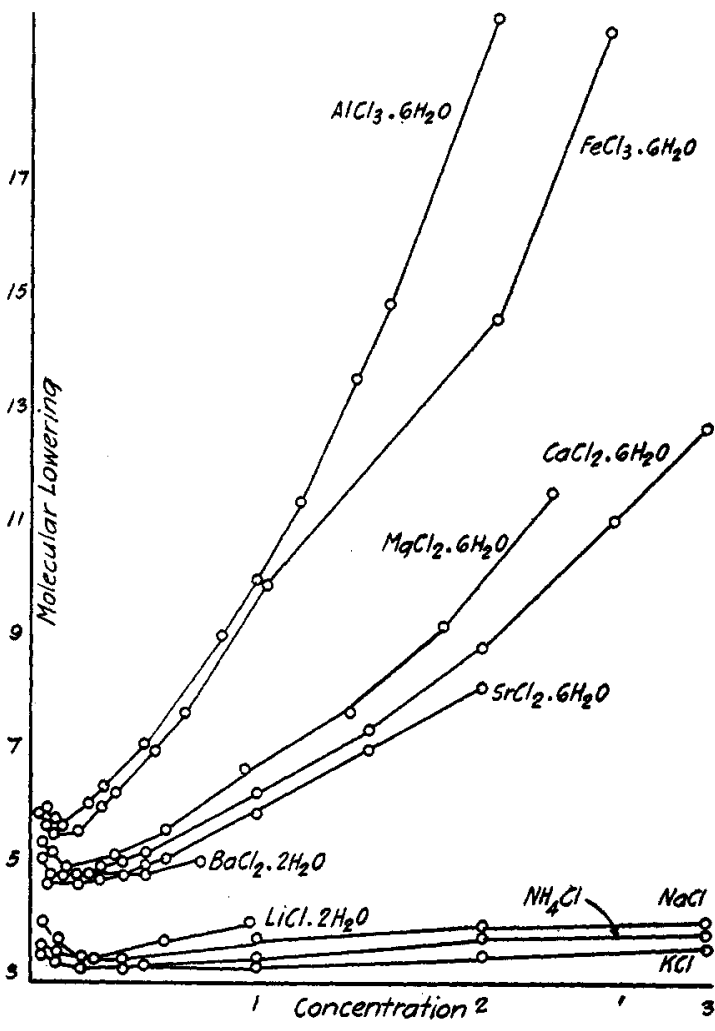

Fig. 2. perimentally from solutions of the same concentration as the solutions used in the work on the V. C. of water, neverthelesss they serve, in a general way, the present purpose, for they do represent, for the most part, results obtained from equimolecular solutions.

Taking up particular comparisons between the V. C. and heat of solution, it is to be noted that the heat of solution of $\mathrm{LiCl}$ is +8.4 , which suggests that considerable chemical action between solute and solvent in the act of solution takes place. This would mean the formation of hydrates, and a consequent retardation of the V. C. On the other hand, the heats of solution of $\mathrm{NaCl}, \mathrm{NH}_{4} \mathrm{Cl}$ and $\mathrm{KCl}$ are negative, thereby showing less hydration in solution than in the case of $\mathrm{LiCl}$. Consequently,

${ }^{1}$ For a review of this subject, see "Hydrates in Solution," E. W. Washburn, Tech. Quart., 2I, 4II (I908). 
the values of the $V$. C. for these 3 salts ought to be less. The results obtained experimentally for the 3 compounds are in excellent agreement with the theory. Further, the values of the V. C. for the same 3 salts run directly parallel to their heats of solution. Similar comparisons can be made between other groups of like compounds.

TABLE III.

The Velocity of Crystallization of Aqueous Solutions of Chlorides. Temperature $-7.0^{\circ}$.

\begin{tabular}{|c|c|c|c|c|c|c|c|}
\hline Substance. & $\begin{array}{l}\text { Conc. } \\
\text { gram mol } \\
\text { per liter. }\end{array}$ & $\begin{array}{c}\text { Time per } \\
\text { meter } \\
\text { in sec. }\end{array}$ & $\begin{array}{l}\text { Conc. } \\
\text { gram mol } \\
\text { per liter. }\end{array}$ & $\begin{array}{c}\text { Time per } \\
\text { meter } \\
\text { in sec. }\end{array}$ & $\begin{array}{l}\text { Conc. } \\
\text { gram mol } \\
\text { per liter. }\end{array}$ & $\begin{array}{l}\text { Time per } \\
\text { meter } \\
\text { in sec. }\end{array}$ & $\begin{array}{l}\text { solution } \\
\mathbf{K}_{\mathbf{g}} \text {. cal. }\end{array}$ \\
\hline ure water. & . & 34.0 & & & $\ldots$ & $\cdots$ & \\
\hline${ }_{2} \mathrm{O}$. & $0.5 M$ & 204.0 & $0.25 M$ & 70.0 & $0.125 M$ & 8 & +8.40 \\
\hline $\mathrm{NaCl}$. & $0.5 M$ & 132.5 & $0.25 M$ & $47 \cdot 4$ & $0.125 M$ & & -1.01 \\
\hline Cl. & $0.5 M$ & 97.0 & $0.25 M$ & $4 I \cdot 5$ & $0.125 M$ & & $-4 \cdot 44$ \\
\hline $\mathrm{Cl}$ & $0.5 M$ & 154.0 & $0.25 M$ & $5 I .0$ & $5 M$ & 0.0 & \\
\hline $\mathrm{H}$ & $0.5 M$ & 0 & 0. & 42.0 & $M$ & & -3.88 \\
\hline $\mathrm{dC}$ & $M$ & o & $5 M$ & 8 & $M$ & & +0.76 \\
\hline $\mathrm{n}$ & $M$ & .0 & $0.25 M$ & 0 & $5 M$ & & +1.54 \\
\hline $\mathrm{O}$ & $M$ & 362.0 & $0.25 M$ & o & $5 M$ & o & -4.93 \\
\hline $\mathrm{C}$ & $M$ & 600.0 & $0.25 M$ & I 48.0 & 5 & & -7.50 \\
\hline $\mathrm{aC}$ & & 458.0 & $0.25 M$ & & 0. I25 $M$ & & $-4 \cdot 30$ \\
\hline $\operatorname{AgC}$ & $0.5 M$ & 0 & $0.25 M$ & & $0.125 M$ & 65.0 & +2.95 \\
\hline : & & 583.0 & $M$ & & $5 M$ & & -1.16 \\
\hline & & .0 & & & $M$ & & -2.85 \\
\hline & & & & & $0.125 M$ & & $+4.2 \mathrm{I}$ \\
\hline & $0.5 M$ & 3420.0 & & & o.r25 $M$ & & \\
\hline $\mathrm{eCl}_{3} .6 \mathrm{H}_{2} \mathrm{O} \ldots \ldots$ & $0.5 M$ & 3460.0 & $0.25 M$ & 320.0 & $0.125 M$ & 99.8 & . \\
\hline
\end{tabular}

Sodium sulfate crystallizes with Io molecules of water, yet in spite of its large content of crystal water this salt retards the $\mathrm{V}$. C. but very little more than does $\mathrm{K}_{2} \mathrm{SO}_{4}$, which crystallizes anhydrous. This apparent discrepancy can be understood when it is noted that the heat of solution of $\mathrm{Na}_{2} \mathrm{SO}_{4} \cdot 10 \mathrm{H}_{2} \mathrm{O}$ is -18.76 and that of $\mathrm{K}_{2} \mathrm{SO}_{4}-6.4$. From these figures it would appear that $\mathrm{Na}_{2} \mathrm{SO}_{4}, \mathrm{IOH}_{2} \mathrm{O}$ when dissolved in water does not combine with the solvent to form hydrates to the same comparative degree as does $\mathrm{K}_{2} \mathrm{SO}_{4}$. The reason for this is difficult to explain apart from the statement that it is a specific property of the individual compound. In this connection it might be well to recall the fact that the hydrates of sodium sulfate break down completely at $34^{\circ}$, which perhaps further indicates that this compound does not have the capacity for combining with water much beyond that exhibited in its crystal formation of the decahydrate.

The difference in the heats of solution of $\mathrm{CuSO}_{4}$ and of $\mathrm{MnSO}_{4}$ gives an explanation why the manganese salt with 4 molecules of water of crystallization retards the V. C. to a greater extent than does the copper salt with 5 molecules of water. The vitriols have approximately the 
same values for the heat of solution, and, as might be expected, they retard the V. C. to about the same extent.

Change in V.C. with Successive Crystallization.-An interesting and important phenomenon must be mentioned regarding the change in the retarding effect of many of the solutions with successive crystallizations. It was observed in the preliminary work ${ }^{1}$ that $\mathrm{ZnSO}_{4} .7 \mathrm{H}_{2} \mathrm{O}$ and $\mathrm{MgSO}_{4 .-}$ $7 \mathrm{H}_{2} \mathrm{O}$ gave different values for the $\mathrm{V}$. C. with repeated trials. This was

TABLE IV.

The Velocity of Crystallization of Aqueous Solutions of Sulfates. Temperature $-7.0^{\circ}$.

\begin{tabular}{|c|c|c|c|c|c|c|c|}
\hline Substa & $\begin{array}{l}\text { Conc. } \\
\text { gram mol } \\
\text { per liter. }\end{array}$ & $\begin{array}{l}\text { Time per } \\
\text { meter in } \\
\text { seconds. }\end{array}$ & $\begin{array}{l}\text { Conc. } \\
\text { gram mol } \\
\text { per liter. }\end{array}$ & $\begin{array}{l}\text { Time per } \\
\text { meter in } \\
\text { seconds. }\end{array}$ & $\begin{array}{l}\text { Conc. } \\
\text { gram mol } \\
\text { per liter. }\end{array}$ & $\begin{array}{l}\text { Time per } \\
\text { meter in } \\
\text { seconds. }\end{array}$ & $\begin{array}{l}\text { Heat of } \\
\text { solution. } \\
\text { Kg. cal. }\end{array}$ \\
\hline${ }_{2} \mathrm{SO}_{4}$. & $0.5 M$ & .. & $0.25 M$ & $63 \cdot 5$ & $0.125 M$ & $37 \cdot 5$ & -6.4 \\
\hline 4. $\mathrm{IOH}_{2} \mathrm{O}$. & $0.5 M$ & & $0.25 M$ & 77.0 & $0.125 M$ & I & -18.76 \\
\hline 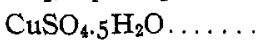 & $0.5 M$ & 218.0 & $0.25 M$ & 109.0 & $0.125 M$ & 56.0 & -2.75 \\
\hline$n$ & $0.5 M$ & 240.0 & $0.25 M$ & II 8.0 & $0.125 M$ & & +0.04 \\
\hline Cas & $0.5 M$ & 238.0 & $0.25 M$ & I06.0 & $0.125 M$ & & +2.66 \\
\hline $\mathrm{NisO}$ & $0.5 M$ & 238.0 & $0.25 M$ & Io & $0.125 M$ & & -4.25 \\
\hline ost & $M$ & 258.0 & $M$ & 10 & $5 M$ & & - \\
\hline . & & .0 & $M$ & & $M$ & & -4.26 \\
\hline . & $0.5 M$ & .0 & $5 M$ & II & 0.125 $M$ & .0 & -3.80 \\
\hline $\mathrm{H}_{2} \mathrm{O} \ldots$ & $0.5 M$ & 3960.0 & $0.25 M$ & 650.0 & $0.125 M$ & 204.0 & +8.20 \\
\hline $\mathrm{r}_{2}\left(\mathrm{SO}_{4}\right)_{8} \cdot \mathrm{I} 8 \mathrm{H}_{2} \mathrm{O} \ldots$ & $0.5 M$ & & $0.25 M$ & 465.0 & $0.125 M$ & 165.0 & +6.20 \\
\hline
\end{tabular}

explained on the supposition that the molecules of the solute became associated. At present, with more data at hand, this same phenomenon can be explained on the theory of hydration in solution and in the following way. The first time a newly prepared solution is frozen, the hydrates may be completely or in part broken up. The tube is then placed in a bath of warm water, the ice crystals quickly melted, and then removed to an ice-water bath and then back again to the crystallization bath. The second reading, in seconds per meter, is less than the first, thereby showing less hydration. It would appear that from the time of the removal of the tube from the bath after the first crystallization till the second reading was obtained, the substance had not had sufficient

TABLE $V$.

The Change in V. C. with Successive Crystallizations.

\begin{tabular}{|c|c|c|c|c|c|}
\hline Substance. & Conc. & $\begin{array}{l}1 \text { st crys. } \\
\text { Time per } \\
\text { meter. }\end{array}$ & $\begin{array}{l}\text { 2nd crys. } \\
\text { Time per } \\
\text { meter. }\end{array}$ & $\begin{array}{l}\text { 3rd crys. } \\
\text { Time per } \\
\text { meter. }\end{array}$ & $\begin{array}{l}\text { After stand- } \\
\text { ing. Time } \\
\text { per meter. }\end{array}$ \\
\hline $\mathrm{ZnSO}_{4.7} \mathrm{H}_{2} \mathrm{O}$. & 0.5 & $258.0 \mathrm{sec}$. & $240.0 \mathrm{sec}$ & $\cdot$ & $260.0 \mathrm{sec}$ \\
\hline $\mathrm{Al}_{2}\left(\mathrm{SO}_{4}\right)_{8 .} \mathrm{I} 8 \mathrm{H}_{2} \mathrm{O}$ & $25 M$ & $705.0 \mathrm{sec}$ & $605.0 \mathrm{sec}$ & $645.0 \mathrm{sec}$ & $.0 \mathrm{sec}$ \\
\hline $\mathrm{MnCl}_{2.4} \mathrm{H}_{2} \mathrm{O}$. & $0.5 M$ & $660.0 \mathrm{sec}$ & $560.0 \mathrm{sec}$. & $565.0 \mathrm{sec}$ & $668.0 \mathrm{sec}$ \\
\hline $\mathrm{CaCl}_{2} .6 \mathrm{H}_{2} \mathrm{O} \ldots$ & $0.5 M$ & $520.0 \mathrm{sec}$ & $455.0 \mathrm{sec}$ & $460.0 \mathrm{sec}$ & 517.0 sec. \\
\hline $\mathrm{NiCl}_{2}, 6 \mathrm{H}_{2} \mathrm{O}$ & 0.5 & $680.0 \mathrm{sec}$ & $585.0 \mathrm{sec}$. & 580.0 sec. & $682.0 \mathrm{sec}$ \\
\hline $\mathrm{BaCl}_{2}, 2 \mathrm{H}_{2} \mathrm{O} \ldots$ & 0.5 & $390.0 \mathrm{sec}$ & $362.0 \mathrm{sec}$. & $362.0 \mathrm{sec}$. & $388.0 \mathrm{sec}$. \\
\hline $\begin{array}{l}\text { Isopropyl alcohol } \ldots \ldots \ldots \ldots \ldots \\
\text { Gelatin I5 g. per liter........ }\end{array}$ & $\begin{array}{l}0.5 \\
\ldots\end{array}$ & $\begin{array}{l}560.0 \text { sec. } \\
94.0 \text { sec. }\end{array}$ & $\begin{array}{l}520.0 \mathrm{sec} . \\
86.4 \mathrm{sec} .\end{array}$ & $\begin{array}{l}510.0 \mathrm{sec} \\
72.5 \mathrm{sec}\end{array}$ & to sec. \\
\hline
\end{tabular}

1 Walton and Brann, ThIS Journal, 38, i I6 I (I9I6). 
time to become again hydrated to the extent it was when the solution was first made.up. Often 3 readings were taken before a constant value could be obtained. But in every case, if the solution was allowed to stand from a half hour to an hour or more in the tube, the V. C. reverted to the first value. Table $\mathrm{V}$ gives a list of compounds that showed this phenomenon. Colloids of the emulsoid type, such as gelatin and dextrin, exhibited this behavior to a marked degree.

The Influence of the Difference in Freezing Points of Solutions on the V. C. of Water.-The different solutions which have been worked with have different freezing points. Consequently, at $-7.0^{\circ}$, the temperature at which the experiments were conducted, the solutions would not all be equally undercooled. Table VI gives a list of compounds, the freezing points of their solutions and their effects on the retardation of the V.C. of water. By studying the table, it soon becomes evident that the difference in the freezing points of two like solutions does not bear much relation to the value of the $\mathrm{V} . \mathrm{C} . \mathrm{KCl}$ and $\mathrm{LiCl} .2 \mathrm{H}_{2} \mathrm{O}$ have freezing points nearly identical with each other, yet the influence of the latter on the V. C. is in sharp contrast to that of the former. A similar comparison of the results obtained with other chlorides shows that the difference in the amounts of undercooling in influencing the values of the V. C. is practically negligible.

\section{TABLE VI.}

The Freezing Points of $0.25 M$ Solutions of Chlorides.

(Values Are Obtained by Extrapolation from Jones' Tables.)

\begin{tabular}{|c|c|c|}
\hline Compound. & $\begin{array}{l}\text { Lowering of } \\
\text { f. p. of water. }\end{array}$ & $\begin{array}{l}\text { V.C. Time per } \\
\text { meter in seconds. }\end{array}$ \\
\hline $\mathrm{HCl}$. & 0.870 & 51.0 \\
\hline $\mathrm{NaCl}$. & 0.870 & $47 \cdot 4$ \\
\hline $\mathrm{KCl} \ldots \ldots$ & 0.850 & $41 \cdot 5$ \\
\hline $\mathrm{L}, \mathrm{iCl} .2 \mathrm{H}_{2} \mathrm{O} \ldots$ & . 0.910 & 70.0 \\
\hline $\mathrm{BaCl}_{2} \cdot 2 \mathrm{H}_{2} \mathrm{O}$. & . 1.175 & 83.0 \\
\hline $\mathrm{CoCl}_{2} .6 \mathrm{H}_{2} \mathrm{O}$ & . $\quad 1.215$ & 140.0 \\
\hline 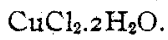 & $\ldots \quad 1.215$ & 109.0 \\
\hline $\mathrm{CaCl}_{2} .6 \mathrm{H}_{2} \mathrm{O}$. & .. I. 1255 & II 2.0 \\
\hline $\mathrm{MgCl} \cdot 6 \mathrm{H}_{2} \mathrm{O}$ & I. 280 & 163.0 \\
\hline
\end{tabular}

The Effects Produced by Alcohols and Other Compounds Containing Hydroxyl Groups.-In general, it would be supposed that organic compounds containing hydroxyl groups, when dissolved in water, would be more likely to combine with the solvent than would compounds without hydroxyl groups. Further, a substance with one hydroxyl group such as ethyl alcohol would not be expected to have as great a combining power with water as perhaps a substance such as glycerol with 3 hydroxyl groups. Table VII and Fig. 3 give the results obtained with a series of hydroxyl compounds. The behavior of these compounds is not at all that which might be expected. Resorcinol, with two hydroxyl groups, retards the 
V. C. much more than does pyrogallol with three. Ethyl alcohol slows up the V. C. to a much greater extent than either glycol or glycerol. And again, the two latter compounds containing different numbers of hydroxyl groups have approximately the same influence on the V. C. Succinic acid, too, retards the V. C. considerably more than tartaric acid. From the standpoint of hydrates in solution relative to the $\mathrm{V}$. $\mathrm{C}$. of water, it must be concluded that the amount of hydration which a hydroxyl compound undergoes in solution cannot be adjudged by the num-

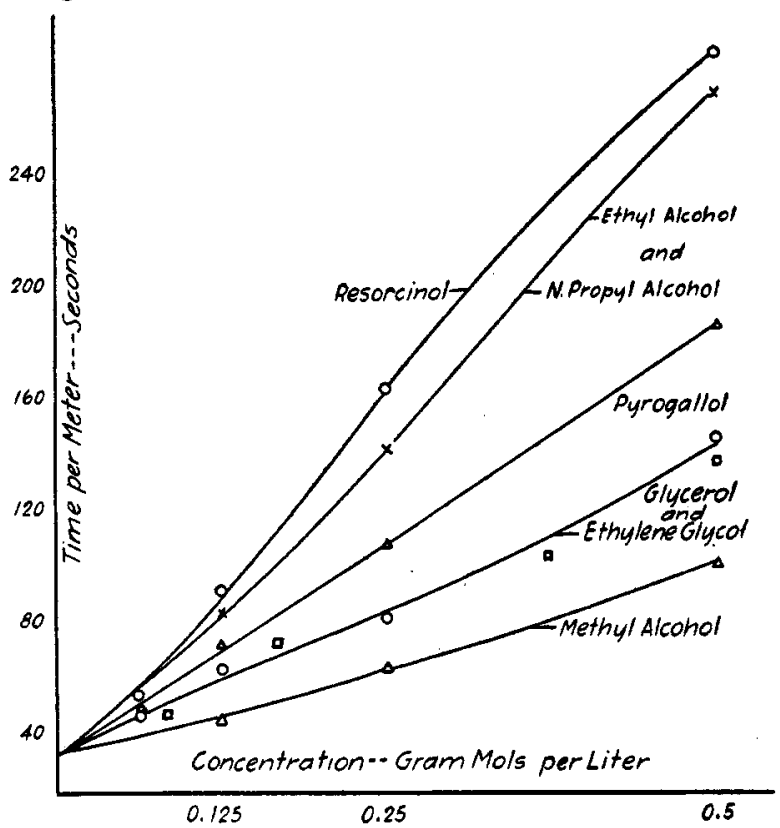

Fig. 3. ber of hydroxyl groups which that compound contains.

In this connection, the work of Padoa and Corsini ${ }^{1}$ on the diffusion of various non-electrolytes is of interest. They calculated that methyl alcohol, glycerol and ethyl alcohol were hydrated in solution in the following order: methyl alcohol, I.9; glycerol, 8.9; ethyl alcohol, I5.0.

\section{TABIE VII.}

The Velocity of Crystallization of Aqueous Solutions of Hydroxyl Compounds.

Temperature-7.0 .

\begin{tabular}{|c|c|c|c|c|c|c|}
\hline ubstance & $\begin{array}{c}\text { Conc. } \\
\text { gram mol } \\
\text { per liter. }\end{array}$ & $\begin{array}{l}\text { Time per } \\
\text { meter in } \\
\text { seconds. }\end{array}$ & $\begin{array}{l}\text { Conc. } \\
\text { gram mol } \\
\text { per liter. }\end{array}$ & $\begin{array}{l}\text { Time per } \\
\text { meter in } \\
\text { seconds. }\end{array}$ & $\begin{array}{l}\text { Conc. } \\
\text { gram mol } \\
\text { per liter. }\end{array}$ & $\begin{array}{l}\text { Time per } \\
\text { meter in } \\
\text { seconds. }\end{array}$ \\
\hline Icohol & $0.5 M$ & 102.5 & $0.25 M$ & 65.0 & $0.125 M$ & 46.5 \\
\hline & $0.5 M$ & 272.0 & $0.25 M$ & 143.0 & $0.125 M$ & 94.0 \\
\hline & $0.5 M$ & 270.0 & $0.25 M$ & .0 & $0.125 M$ & $3 \cdot 7$ \\
\hline & $0.5 M$ & 138.0 & $0.25 M$ & .0 & o.125 $M$ & 60.0 \\
\hline & $0.5 M$ & 146.0 & $0.25 M$ & 82.0 & $0.125 M$ & 60.0 \\
\hline & $0.5 M$ & 285.0 & $0.25 M$ & I63.5 & $0.125 M$ & 92.0 \\
\hline & $0.5 M$ & 186.5 & $0.25 M$ & 108.5 & $0.125 M$ & 74.5 \\
\hline & $0.1 M$ & 170.0 & $0.25 M$ & . & $0.125 M$ & . \\
\hline & $0.1 M$ & 138.0 & $0.25 M$ & . & $0.125 M$ & \\
\hline
\end{tabular}

${ }^{1}$ Padoa and Corsini, Atti accad. Lincei, [5] 24, ii, 46I-467 (1915).

${ }^{2}$ Readings taken at $-9.1^{\circ}$ and with different tubes from those used to obtain other values listed in table. 
The numerical values give the number of molecules of water combined with one molecule of the compound. This is in excellent agreement with

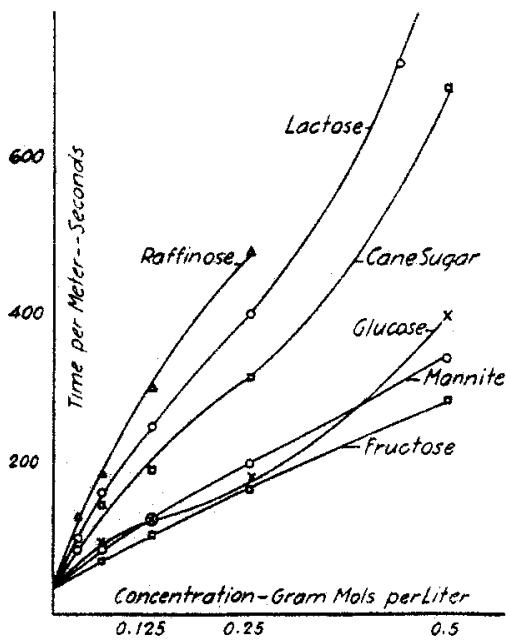

Fig. 4 . the effects of these same substances on the V. C. of water.

The Effects Produced on the V. C. of Water by Certain Sugars.-From the standpoint of the effects on the V.C. of water of all the sugars studied, these compounds are hydrated in solution to no small degree. Jones, ${ }^{1}$ from his work on the freezing points of some of the sugars, concluded that glucose, lactose and mannite were hydrated hardly at all, but that fructose and cane sugar showed considerable hydration in solution. The results obtained with the V. C. are shown in Table VIII and in Fig. 4. It is evident immediately that these results do not entirely agree with those found by Jones.

TABLE VIII.

The Velocity of Crystallization of Aqueous Solutions of Certain Sugars.

Cane Sugar.

\begin{tabular}{|c|c|}
\hline \multicolumn{2}{|c|}{ Cane Sugar. } \\
\hline $\begin{array}{l}\text { Conc. } \\
\text { gram mol } \\
\text { per liter. }\end{array}$ & $\begin{array}{l}\text { Time } p \\
\text { meter } \\
\text { second }\end{array}$ \\
\hline 0.5 & 700.0 \\
\hline 0.25 & 316.0 \\
\hline o. I25 & 195.0 \\
\hline 0.0625 & 149.0 \\
\hline 0.03125 & 90.0 \\
\hline \multicolumn{2}{|c|}{ Glucose. } \\
\hline 0.5 & 395.0 \\
\hline 0.25 & 180.0 \\
\hline 0.125 & 125.0 \\
\hline 0.0625 & 88.0 \\
\hline
\end{tabular}

Temperature $-7.0^{\circ}$.

$\overbrace{\begin{array}{c}\text { Conc. } \\ \text { gram mol } \\ \text { per liter. }\end{array}}^{\text {Lactose. }} \begin{aligned} & \begin{array}{l}\text { Time per } \\ \text { meter in } \\ \text { seconds. }\end{array}\end{aligned}$

$\overbrace{\begin{array}{c}\text { Conc. } \\ \text { gram mol }\end{array}}^{\text {Fructose. }}$

0.5

0.25

0.125

0.0625

905.0

400.0

247.0

159.0

100.0

\section{5}

seconds.

0.03125

0.25

285.0

0.125

165.0

0.0625

105.0

70.0

\begin{tabular}{lr}
\multicolumn{2}{c}{ Raffinose } \\
\hline$\ldots$ & $\ldots$ \\
0.25 & 480.0 \\
0.125 & 299.0 \\
0.0625 & 190.0 \\
0.03125 & 124.0 \\
0.015625 & 68.0
\end{tabular}

\begin{tabular}{lr}
\hline .5 & $\begin{array}{l}340.0 \\
0.0\end{array}$ \\
0.25 & 180.0 \\
0.125 & 125.0 \\
0.0625 & 83.0
\end{tabular}

. $\ldots$

One of the most significant things in connection with the sugars is the general shape of the curves plotted in Fig. 4. This general trend of direction is very unlike that met with in considering the inorganic compounds, Fig. I, for example. With the sugars, the curves follow closely the lines of ordinates in the dilute solutions instead of the lines of abscissae as

1 Loc. cit. 
with the inorganic chlorides. An explanation of this phenomenon can be found on the basis that the sugars are very highly hydrated in dilute solutions, and therefore retard the V. C. to an unusual degree. It is worthy of notice that the effects produced by the alcohols are represented by curves which, regarding general direction, lie midway between those of the sugars and the inorganic chlorides. This means that, in comparing these 3 classes of compounds, the chlorides are the least hydrated, the alcohols more hydrated and the sugars most hydrated in dilute solutions.

The Mutarotation of Sugars and the V.C. of Water.-Fischer ${ }^{1}$ first put forward an explanation of the mutarotation of sugars on the basis that these substances are hydrated in solution. Later, Lowry² suggested that the same phenomenon was due, not to hydration, but to a re-arrangement within the molecule of the compound. Further work of Lowry ${ }^{3}$ and of Armstrong ${ }^{4}$ seemed to confirm this latter view as to the nature of mutarotation. Hudson, ${ }^{5}$ from his studies with lactose, concluded that the change in rotation of this sugar was due to a gradual change in its state of hydration in solution. In a later paper ${ }^{b}$ he suggested that the two theories here mentioned might be considered as identical views and that there was no good ground for argument between them.

The effects of glucose and of lactose on the V. C. of water are interesting from the standpoint of these two theories on mutarotation. In the second communication ${ }^{7}$ on this work, experimental data on the V. C. of solutions of glucose were presented which suggested that the hydrate hypothesis for the change in rotation of glucose was the correct one. However, when the present work was undertaken with tubes that were more satisfactory regarding the reliability of readings obtained, it was thought advisable to repeat the former experiments that had been made with glucose. The outcome was that no difference in the V. C. was observed between solutions prepared from the anhydrous and the crystallized substance either when freshly made up or after standing for some days. Further experiments were made with lactose. A quantity of the anhydrous milk sugar was prepared as described by Hudson. ${ }^{8}$ The values of the $\mathrm{V}$. C. of freshly made solutions of both the anhydrous sugar and the hydrated form were found to be identical (see Table IX). If, as it is thought, the chief influence of dissolved substances on the V. C.

1 Ber., 23, 2626 (1890).

$2 J$. Chem. Soc., 75, 2 I I (1899).

s Ibid., 83, I3I4 (I903).

${ }^{4}$ Ibid., 83, I305 (1903).

5 This JoURNAL, 26, IO65 (1904).

- Ibid., 30, I 767 (1908).

7 Walton and Brann, Ibid., 38, 317 (1916).

${ }^{8}$ Ibid., 26, 1065 (1904). 
of water is due to hydration, then from the findings with glucose and lactose, it must be concluded that the phenomenon of mutarotation is not a hydration effect.

TABLE IX.

The Velocity of Crystallization of Aqueous Solutions of Glucose and Lactose.

Temperature $-7.0^{\circ}$.

Lactose (anhydrous)... July 22 I $65.5 \mathrm{sec}$. per meter July 30 I $64.9 \mathrm{sec}$. per meter

Lactose (hydrated).... July $22 \mathrm{I} 66.3 \mathrm{sec}$. per meter July $30 \mathrm{I} 66.7 \mathrm{sec}$. per meter

Glucose (anhydrous).... July $22179.4 \mathrm{sec}$. per meter July 30 180.0 sec. per meter

Glucose (hydrated)..... July $22179.2 \mathrm{sec}$. per meter July $30178.5 \mathrm{sec}$. per meter

The Effects Produced by Colloids on the V. C. of Water.-Hydrosols do not lower the freezing point of water to any appreciable degree. Hence any retardation that these substances may have on the $V$. C. of water is practically independent of the freezing point of the hydrosol, a factor which therefore need not be considered at all as was necessary concerning the V. C. of true solutions.

Further, hydrosols may be conveniently divided into two classes: emulsoids typified by gelatin, and suspensoids typified by ferric hydroxide. It is well recognized that the mechanical properties of these two types are very different. Emulsoids apparently combine with water to a remarkable degree, as shown in the puffing up of gelatin or agar when these substances are in contact with water. On the other hand, suspensoids seem not to have the property of combining with water to such an extent as do emulsoids. It would be expected, therefore, if the retardation of the V.C. of water were chiefly a hydration phenomenon, that emulsoids would have a greater retarding effect than would suspensoids.

Preparation of the Colloid Systems. Gelatin.--The best gelatin commercially obtainable was weighed out dry, soaked into solution and boiled for a short time. This solution when cooled to $-7.0^{\circ}$ solidified. A part of it was again boiled for 5 hours, after which time the non-coagulable B-gelatin, described by Moritz Traube, ${ }^{1}$ was obtained. Both gelatin solutions were used.

Agar-agar-Agar-agar was soaked in $5 \%$ acetic acid for 7 days. It was then washed with distilled water by decantation till free from acetic acid. Each application of wash water was allowed to stand on the agar for half a day. The product was boiled with water and the clear solution filtered away from a small amount of insoluble matter. The resulting hydrosol did not solidify on being undercooled.

Silicic Acid.- This colloid was prepared by dialyzing a very dilute solution of sodium silicate and hydrochloric acid till the usual silver nitrate test showed the absence of chlorides. The hydrosol was then concentrated by distillation under diminished pressure. The resulting solution had the appearance of concentrated sulfuric acid.

1 M. Traube, Reichert and Du Bois Reymond's Arch., 87, (1867). 
Ferric Hydroxide.-A clear solution resulting from the admixture of ferric chloride and ammonium carbonate was dialyzed till all chlorides had disappeared.

Arsenious Sulfide.-Hydrogen sulfide was run into a suspension of arsenic trioxide in boiling water. Excess of hydrogen sulfide was driven out with a current of pure hydrogen.

Starch and Other Colloids. -The starch was prepared from potatoes and was especially purified by centrifugal means. The rest of the colloids lent themselves to a simple preparation, the solid material being weighed out and

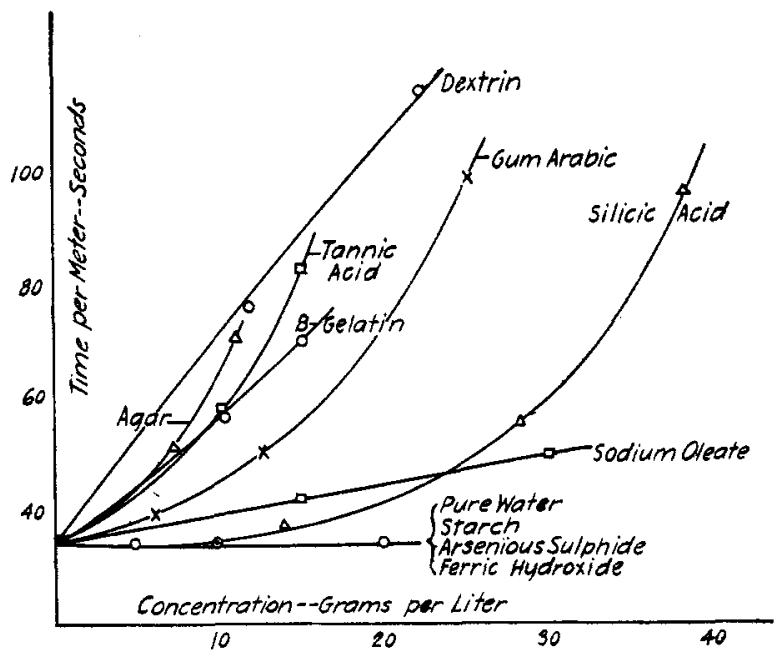

Fig. 5. dispersed throughout a known volume of water.

Discussion of Results.-Fig. 5 gives a graphic interpretation of the data arranged in Table $X$. The difference in the behavior of the two classes of hydrosols is sharply defined. The suspensoids have practically no effect on the $V$. C., a result in harmony with the general mechanical

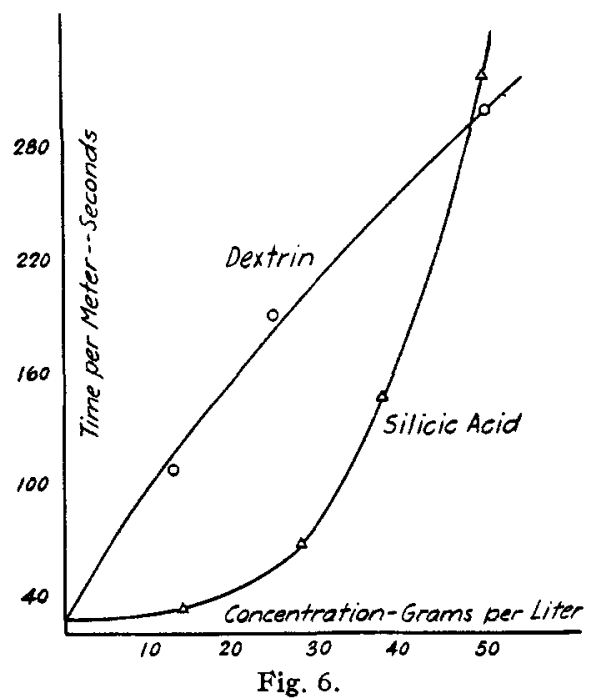
properties of this class, in that they have little attraction for water, a fact well shown in their irreversibility when once coagulated. On the other hand, emulsoids retard the V. C. to a considerable extent, an effect also to be expected. These results show undoubtedly that hydration is a most important factor in the retardation of the $V$. C. of water.

In comparing the relative ability of any one emulsoid to slow down the V. C. with that of the rest, the facts show that the influence each substance is entirely specific. However, points of particular inter- 
est attach themselves to individual colloids. Solutions of both A-gelatin and B-gelatin were used. The A-gelatin solidified in the tube at $-7.0^{\circ}$, while the B-gelatin remained liquid. Both systems were crystallized in the ordinary way and the retarding effect of each was identical.

The V. C of a $4 \%$ hydrosol of dextrin and one of an equivalent concentration of silicic acid, Fig. 6, are practically the same. In lower concentrations of these two hydrosols, the relative effects on the V. C. are in decided contrast. The retardation in the case of the dextrin is approximately proportional to its concentration, whereas with the silicic acid, low concentrations have very little effect on the V. C., hardly more than that exhibited by suspensoids. It is also to be noted that a freshly. prepared $4 \%$ ferric hydroxide hydrosol, Table $\mathrm{X}$, has a marked retarding effect on the V.C. In lower concentrations, it, too, does not retard the V. C. J. M. van Bemmelen ${ }^{1}$ has pointed out that ferric hydroxide hydrosol may behave as an emulsoid at fairly high concentrations. At low concentrations it is a characteristic suspensoid. The difference in the behavior of silicic acid from that of dextrin at low concentrations might well be due to the fact that silicic acid hydrosol is similar tc ferric hydroxide and can play the role of an emulsoid or a suspensoid, depending on the concentration.

TABLE X.

The Velocity of Crystallization of Hydrosols. Temperature $-7.0^{\circ}$.

\begin{tabular}{|c|c|c|c|c|c|c|}
\hline Substance. & $\begin{array}{l}\text { Conc. } \\
\text { grams } \\
\text { per liter. }\end{array}$ & $\begin{array}{l}\text { Time per } \\
\text { meter in } \\
\text { seconds. }\end{array}$ & $\begin{array}{l}\text { Conc. } \\
\text { grams } \\
\text { per liter. }\end{array}$ & $\begin{array}{l}\text { Time per } \\
\text { meter in } \\
\text { [seconds. }\end{array}$ & $\begin{array}{l}\text { Conc. } \\
\text { grams } \\
\text { per liter. }\end{array}$ & $\begin{array}{l}\text { Time per } \\
\text { meter in } \\
\text { seconds. }\end{array}$ \\
\hline$\ldots \ldots \ldots$ & $\cdots$ & 34.0 & . & & $\cdots$ & , \\
\hline Gum arabic,.......... & 25.0 & 100.0 & 12.5 & $52 \cdot 3$ & 6.25 & 40.0 \\
\hline Dextrin ............. & 50.0 & $184 \cdot 7$ & 25.0 & I 26.6 & $12 \cdot 50$ & 76.8 \\
\hline Sodium oleate. & 30.0 & 50.0 & 15.0 & 43.0 & $7 \cdot 50$ & $34 \cdot 5$ \\
\hline Tannic acid & $x_{5}, 0$ & 84.2 & 10.0 & 59.0 & $7 \cdot 50$ & $47 \cdot 7$ \\
\hline Silicic acid.... & 57.0 & 255.0 & 38.0 & 98.0 & 28.50 & 56.0 \\
\hline Agar. & $1 \mathrm{r} .8$ & 72.0 & $7 \cdot 3$ & 50.8 & 3.65 & 36.1 \\
\hline B-Gelati & 15.0 & 71.0 & 10.0 & 58.5 & 5.00 & $4 \mathrm{I}, 5$ \\
\hline Ferric hydroxide. . . . . . . & 40.0 & 59.0 & 20.0 & 22.0 & IO. 00 & 22.0 \\
\hline Potato starch......... & 10.0 & 34.0 & 5.0 & 35.0 & & \\
\hline Arsenious trisulfide. & 20.63 & 33.6 & 10.3 & 34.2 & $\cdots$ & 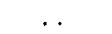 \\
\hline
\end{tabular}

Ferric hydroxide not only has no retarding effect on the V. C. in its dilute solutions, but it actually increases the V. C. This phenomenon was repeatedly observed with this hydrosol. The explanation of it is probably connected with the change in the crystal habit of water. Mention $^{2}$ has been made of the different forms of ice crystals described by Hartman. In all the experiments on the $V . C$. of water with the single exception of the one with ferric hydroxide, the crystallizing surface took a forward-moving spiral course around the inside of the tube. With ferric

${ }^{1}$ J. M. van Bemmelen, "Die Absorption," Dresden, rgro.

"Walton and Brann, Thrs Journal, 38, 317 (I916). 
hydroxide hydrosol, this spiral movement was for the most part absent. Instead, a straight-forward shooting movement down the length of the tube was exhibited, the crystals taking a needle-like form. This rapid forward movement of the growing crystals resulted in bringing about an inoculation of the water yet uncrystallized sooner than if the spiral course were followed. Consequently very rapid crystallization took place. The V. C. under such conditions was actually greater than that of pure water.

General Survey of the Work of the V. C. of Water.-No mathematical statement of any kind has been developed to show the relationships that may exist among the different factors which come into play in the phenomena described in this paper, or to calculate the absolute degree of hydration of any particular substance. The effects of different solutes have been considered from a relative point of view. It has been shown ${ }^{1}$ conclusively that the retarding effects on the V. C. are not proportional to the molecular weight of the dissolved substance. In fact, the author believes that these effects are absolutely specific in nature.

The work with the tubes suggests that a strictly mathematical relationship may exist between the size of the bore of the tube and the V. C., but this can be proved only by further experimental work with a larger variety of tubes.

\section{Summary.}

I. The results of all the experimental work done on the retardation of the V.C. of water brought about by dissolved substances substantiate the proposition that the chief inhibitory influence is the existence of hydrates in solution.

2. The retarding effect on the V. C. has been studied with the following classes of compounds: inorganic chlorides; inorganic sulphates; alcohols and other related organic compounds; sugars; colloids. The relative effects on the V. C. of all these compounds can be best explained on the assumption that they are more or less hydrated in solution.

3. Every substance studied retards the V. C. except ferric hydroxide hydrosol which, in low concentration, increases it.

4. Substances which crystallize with water of crystallization are hydrated in solution more than similar substances that crystallize without water of crystallization.

5. A distinct parallelism between the V. C. and the heat of solution has been shown to exist. This provides exceptionally good evidence that the relative effects on the V. C. are directly connected with hydration phenomena.

6. With alcohols and allied compounds, the retardation of the V. C. is not proportional to the number of hydroxyl groups contained therein, as perhaps might be expected.

1 Walton and Brann, Loc, cit. 
7. Sugars are hydrated to an unusual degree in their dilute solutions.

8. Colloids particularly substantiate the assumption that the retardation of the V. C. is a hydration effect.

9. The V. C. of water has been shown to vary as the size of the bore of the tube. The thickness of wall of the tube apparently has no effect on the V. C.

Io. No mathematical statement has been derived by which the absolute degree of hydration of substances can be calculated. The effects on the V. C. are believed to be specific in nature.

The author desires to express his sincere appreciation of the kind help and suggestions given by Professor James $\mathrm{H}$. Walton, under whose direction the work was outlined and carried to completion.

Madison, Wisconsry.

[CONTRIBUTION FROM THE DEPARTMENT OF ChEMISTRY, UNIVERSITY OF WISCONSIN.] THE EFFECT OF DISSOLVED SUBSTANCES ON THE VELOCITY OF CRYSTALLIZATION OF FORMAMIDE. ${ }^{1}$

\author{
Bx Al,Bert Brann. \\ Received May 7, 1918. \\ Introduction.
}

In the foregoing paper it has been shown that the chief influence of dissolved substances in retarding the $V$. C. of water is probably due to the combination of the solvent and solute to form solvates. It was therefore of interest to find out if analogous phenomena occur in solvents other than water. To determine this point experimentally, formamide was chosen as the best solvent, because it, of all organic liquids, is most closely allied to water in its physical properties.

\title{
Historical.
}

Walden ${ }^{2}$ first pointed out the similarities between formamide and water. Formamide dissolves many of the more common inorganic salts. Bruni and Mannuelli ${ }^{3}$ have shown that just as water hydrolyzes the salts of weak bases, such as those of bismuth and copper, forming unstable basic salts, so formamide, by a process of aminolysis, forms basic salts of these same metals. Rohler ${ }^{4}$ has isolated basic salts of copper, cobalt, nickel and zinc. He has also obtained amidates similar to hydrates, such as $\mathrm{PbCl}_{2} \cdot \mathrm{HCONH}_{2}$. Davis and $\mathrm{Putnam}^{5}$ have determined the tempera-

1 Part of a thesis submitted to the graduate school of the University of Wisconsin as partial fulfilment of the requirements for the degree of Doctor of Philosophy.

${ }^{2}$ Walden, $Z$. phys. Chem., 46, I45 (1903); 55, 230 (1906); 75, 575 (1910); Bull. Imp. Acad. Sci., St. Petersburg, I9I I.

3 Z. Elektrochem., II, 554 (I905).

${ }^{4}$ Ibid., 16, 418 (I9IO).

"Jones, "Conductivities and Viscosities in Solvents," Carnegie Inst. Publication 230. 